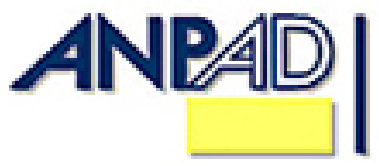

Disponível em

http://www.anpad.org.br/rac

RAC, Rio de Janeiro, v. 18, n. 1, art. 3,

pp. 37-58, Jan./Fev. 2014

$($ oc) EY-No

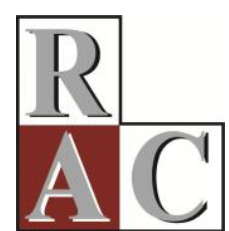

\title{
A Influência da Justiça nos Processos de Recuperação de Falhas no Varejo
}

The Influence of Justice in the Retail Failure Recovery Process

Marcos Antonio da Silva

E-mail: marcosaslj@uol.com.br

Universidade Nove de Julho

Av. Francisco Matarazzo, 612, 05001-100, São Paulo, SP, Brasil.

Evandro Luiz Lopes

E-mail: elldijo@uol.com.br

Universidade Nove de Julho

Av. Francisco Matarazzo, 612, 05001-100, São Paulo, SP, Brasil. 


\title{
Resumo
}

O principal propósito deste estudo é identificar o papel da Justiça percebida, em sua constituição tridimensional, nos antecedentes da Lealdade em um cenário de recuperação de falhas de serviço. Para tanto, realizou-se um survey junto a 604 consumidores oriundos de um banco de dados de um grande varejista brasileiro. Por meio da modelagem de equações estruturais, identificaram-se os relacionamentos entre a Justiça e a Satisfação $\left(r^{2}=0,61\right)$, a Qualidade percebida $\left(r^{2}=0,47\right)$ e a Confiança $\left(r^{2}=0,55\right)$. Além disso, identificou-se como estes construtos se relacionam com a Lealdade $\left(\mathrm{r}^{2}=0,70\right)$ após a falha ter sido recuperada.

Palavras-chave: recuperação de falhas; justiça; lealdade; consumidores.

\begin{abstract}
The primary purpose of this study is to identify the role of perceived justice in its tridimensional structure through the antecedents of loyalty in a service failure recovery scenario. Therefore, we carried out a survey of 604 consumers from a large Brazilian retail company database. Through structural equation modeling, we identified the relationships between justice and satisfaction $\left(r^{2}=0.61\right)$, perceived quality $\left(r^{2}=0.47\right)$ and trust $\left(r^{2}=0.5\right)$. In addition, we identified how these constructs relate to loyalty $\left(r^{2}=0.70\right)$ after the failure has been remedied.
\end{abstract}

Key words: failure recovery; justice; loyalty; consumer. 


\section{Introdução}

Já é sabido pelas organizações que apenas a qualidade dos produtos ou seus serviços não é suficiente para manter ou ampliar uma posição estratégica de mercado (Jones \& Sasser, 1995; Parvatiyar \& Sheth, 2000). Com isso, nota-se a preocupação dos gestores das organizações em transformar as operações transacionais em interações mais relacionais com os seus consumidores (Garbarino \& Johnson, 1999). Esse novo ambiente relacional fez com que as empresas percebessem cada vez mais que grande parte do sucesso dos negócios depende da habilidade de manter seus clientes atuais satisfeitos e, assim, leais aos seus processos comerciais (Blodgett, Hill, \& Tax, 1997). Nesse cenário, uma das formas de enaltecer o relacionamento com os consumidores é demonstrada por meio dos investimentos que as organizações realizam buscando a excelência em seus processos comerciais e, em especial, nos processos de recuperação de suas falhas de serviço, sendo que este último é tido como um fator importante de diferenciação e manutenção da Lealdade de seus consumidores (Tax, Brown, \& Chandrashekaran, 1998).

Estudos anteriores já especificaram o conceito de Justiça e também como esse construto afeta a percepção dos consumidores (Blodgett et al., 1997; Tax et al., 1998). O conceito de Justiça pode ser entendido em três diferentes dimensões: na forma de Justiça distributiva - sob o conceito da equidade entre os participantes de uma transação (Tax et al., 1998); na forma de Justiça processual, quando se analisam as políticas e procedimentos utilizados pelas organizações durante a solução dos processos (Blodgett et al., 1997; Tax et al., 1998); e pela Justiça interpessoal, quando se refere ao tipo de tratamento prestado pelos funcionários e pela organização durante o episódio da solução dos problemas (Magnini, Ford, Markowski, \& Honeycutt, 2007; Tax et al., 1998).

Já se contam alguns estudos sobre a percepção da Justiça nos processos de recuperação de falhas (Lin, Wang, \& Chang, 2011; Matos \& Leis, 2013; Maxham \& Netemeyer, 2002; Stefan, Bowen, \& Johnston, 2009; Tax et al., 1998). No Brasil, a principal abordagem sobre o tema está sintetizada nos estudos realizados por Santos e Fernandes (2007), aplicado em concessionárias de automóveis estabelecidas em Porto Alegre (RS), e pelos mesmos autores, em 2008, com consumidores de empresas aéreas e cliente de bancos. Apesar da relevância e originalidade dos estudos realizados por esses autores, verifica-se a existência de lacunas em ambas as abordagens, como, por exemplo, a falta da análise conjunta de um maior composto de antecedentes da Lealdade e a ausência da aplicação do modelo em ambientes comerciais altamente concorrenciais, que apresentem barreiras de saída mais baixas. A indicação desses hiatos consta dos próprios estudos de Santos e Fernandes (2007, p. 48), quando eles enfatizam a existência de "um campo fértil que necessita de pesquisas que explorem o assunto com maior profundidade".

Este estudo procura apresentar um modelo mais robusto com uma investigação que utiliza uma maior quantidade de variáveis antecedentes à Lealdade dos consumidores. Para isso, esta pesquisa se pautou em entender a percepção dos consumidores sobre os tipos de Justiça presentes nos resultados recebidos de suas indicações de falhas sofridas nas relações de troca com um varejista nacional e na influência dessa percepção nos antecedentes da Lealdade. Com isso, o objetivo principal deste trabalho é identificar a influência da Justiça nos antecedentes da Lealdade após um processo de recuperação de falhas, e responder a seguinte questão de pesquisa: Qual a influência da Justiça nos antecedentes da Lealdade dos consumidores após um processo de recuperação de falhas no varejo? Com o objetivo de responder tal questão, este trabalho está estruturado em cinco seções: além desta breve introdução, o referencial teórico, o método utilizado, os resultados observados e, finalmente, a seção que trata da discussão dos resultados e das conclusões e considerações finais. 


\section{Referencial Teórico}

O objetivo desta seção é fornecer os subsídios teóricos necessários sobre os principais conceitos acadêmicos que fazem parte do contexto de recuperação de falhas, da percepção de Justiça, da Lealdade e de seus principais antecedentes.

\section{Os processos de recuperação de falhas}

A disseminação das propostas de um relacionamento mais específico com os consumidores desencadeou a criação de diversas ações voltadas para este fim. Sendo assim, múltiplas operações resultaram na criação de diferentes serviços que foram desenvolvidos e implantados pelas empresas (Parvatiyar \& Sheth, 2000). A inevitável ocorrência de falhas nesses serviços propiciou a criação de processos de recuperação, independente se tais serviços são direcionados ou não aos processos de fidelização dos consumidores (Tax et al., 1998). Segundo Berry e Parasuraman (1991) e Tax, Brown e Chandrashekaran (1998), devido às características de intangibilidade dos serviços, pela existência de certa interdependência operacional e pelo excessivo contato entre clientes e funcionários; o momento do gerenciamento da reclamação pode ser traduzido como o "momento crítico da verdade" na manutenção e desenvolvimento de um relacionamento em longo prazo, resultando em um fator decisivo para a manutenção de posições estratégicas em muitos setores de negócio. Opinião semelhante é apresentada por Blodgett, Wakefield e Barnes (1995), quando dizem que varejistas e prestadores de serviço devem entender as respostas aos reclamantes como uma oportunidade de solidificar e fortalecer o relacionamento com seus clientes.

Segundo Singh (1991), o ato de reclamar pode ser visto como parte de um conjunto de possíveis respostas de clientes a experiências de compras ou de serviços que geraram insatisfação. Em geral, essas opções incluem a denúncia formal, buscando reparação (reembolso, troca, reparo ou desculpa etc.), processos de comunicação negativa boca a boca (ou seja, falar para outras pessoas sobre uma insatisfação), desistência do relacionamento, saindo do ambiente comercial com a promessa de nunca mais voltar para consumir, e entrar em contato com terceiros para expor a situação de forma a denegrir a qualidade operacional e/ou comercial da empresa (reclamações nos meios de comunicação) (Blodgett, Granbois, \& Walters 1993; Singh, 1991).

O aspecto comercial positivo das primeiras respostas aos consumidores está nas evidências consideráveis de que, se uma empresa trata das reclamações imediatamente, além de reduzir a incidência da comunicação negativa boca a boca e de recomendações negativas a terceiros (Lin et al., 2011), aumenta a probabilidade de recompra desses queixosos, que, de forma significante, podem passar a emitir uma comunicação boca a boca positiva (espalhando a afeição, bom relacionamento etc.), podendo se tornar mais leais, caso percebam atenção imediata e um elevado grau de Justiça na solução proposta (Blodgett, Wakefield, \& Barnes, 1995). Magnini, Ford, Markowski e Honeycutt (2007) também chegaram à conclusão de que a resposta imediata da empresa aos reclamantes oferece uma oportunidade única para modelar a Satisfação do cliente e que a mesma pode aumentar, contanto que o cliente perceba esse esforço de recuperação como uma ação legítima e sincera de correção da falha, em vez de um simples esforço de relações públicas.

Segundo Hess, Ganessan e Klein (2003), a quantidade de ocorrência de falhas também influencia a percepção dos clientes e, devido à quantidade de interações entre os agentes, significa uma reserva importante de informações sobre a Satisfação dos clientes para as empresas. Apesar de reconhecer o número de interações com os clientes como um fator importante no processo de Satisfação dos mesmos, Magnini et al. (2007) salientam não ser esse um aspecto significativo, pois essa relação é moderada por uma série de influências contextuais, e os pesquisadores devem ter uma abordagem mais refinada para analisar os processos de recuperação. Segundo estes autores, uma variável extremamente significativa na avaliação da Satisfação dos clientes diante de um processo de recuperação de falhas é a gravidade da ocorrência. Se a falha experimentada pelo cliente for muito grande, nenhuma desculpa razoável ou reparação pode criar uma recuperação significativa o suficiente 
para restabelecer os patamares de Satisfação, Confiança e Qualidade, percebidas antes da ocorrência da mesma (Magnini et al., 2007). O efeito da severidade da falha na Satisfação dos clientes também foi verificado por Matos e Leis (2013), que observaram o fenômeno tanto no Brasil quanto na França.

\section{Os processos de Justiça}

Sendo a reclamação sobre a falha de um serviço, um momento crítico do relacionamento entre fornecedores de serviços e consumidores (Stefan et al., 2009), compreender como o consumidor recebeu o processo de resolução do seu problema passou a ser um dos principais desafios dos gestores das organizações. Sendo assim, a forma, o modo e a quantidade de Justiça que foi aplicada na resolução da reclamação passam a ser fatores decisivos no entendimento dos consumidores (Tax et al., 1998). Segundo Tax et al. (1998), o tratamento das reclamações pode ser visto como uma sequência de manipulações de processos que são iniciados a partir da comunicação da reclamação, e abrange os elementos da interação organizacional que resultam na decisão do tratamento e na apresentação dos resultados ao reclamante. De forma complementar, Bies e Shapiro (1987) ressaltam que cada parte dessa sequência está sujeita a considerações de equidade por parte dos denunciantes e cada resolução proposta pela organização cria um diferente aspecto de Justiça aos consumidores reclamantes.

O entendimento do processo de Justiça, segundo Tax et al. (1998), significa a manipulação da reclamação, envolvendo uma série de eventos relativos ao procedimento de recuperação das falhas que ocorreram e não está baseada apenas na existência da equidade (Justiça distributiva) que trata dos resultados obtidos pós-decisão, mas também de outros dois momentos dessa transação: o que trata diretamente dos processos realizados (Justiça processual) e o que abrange os relacionamentos ocorridos entre os agentes funcionais do processo (Justiça interpessoal). Martinez-tur, Peiró, Ramos e Moliner (2006) corroboram esse pensamento, citando o aspecto distributivo como uma teoria de capital percebida pelos consumidores e que ignora o fator social presente nos conceitos relacionados aos processos e nas interações entre as pessoas.

\section{A lealdade dos consumidores: os seus antecedentes}

Segundo Oliver (1999), Lealdade é um comprometimento profundo em recomprar ou favorecer um produto ou serviço no futuro, evidenciado pela repetição da compra da marca ou do mesmo conjunto de marcas, sendo mais direcionado ao movimento que às escolhas emocionais. Jones e Sasser (1995, p. 94) conceituam a Lealdade dos clientes como "o sentimento de ligação ou de afeto para com as pessoas de uma empresa, seus produtos e seus serviços". Também baseados no aspecto do relacionamento, Singh e Sirdeshmukh (2000) definem Lealdade como um comportamento que demonstra a intenção de manter e ampliar esse relacionamento com o fornecedor de serviço.

No âmbito das operações comerciais, a Lealdade é aferida diretamente pelas pesquisas de comportamento do consumidor, estando vinculada à relação direta entre os clientes e as organizações, sendo multifacetada, complexa e sujeita a Custos de mudança ocasionados por uma multiplicidade de fatores específicos de cada setor comercial (Parente, 2000). Já sob um aspecto financeiro, Reichheld e Sasser (1990) destacam que a existência de uma maior Lealdade dos clientes pode conduzir à redução dos Custos de aquisição de novos consumidores, reduzindo os Custos de manutenção dos negócios e promovendo um caminho menos tortuoso na busca pela lucratividade.

Segundo Dick e Basú (1994), esse posicionamento sobre a movimentação dos clientes tidos como leais com a empresa é explicada pelo fato de que, nessa situação, esses clientes são menos motivados a buscar novas alternativas de negócio, sendo mais resistentes à persuasão dos concorrentes e propensos a propagar a comunicação positiva boca a boca. Os autores ressaltam que esses fatores comportamentais e emocionais não podem ser vistos com a mesma intensidade, e que a Lealdade dos consumidores deve ser classificada em quatro níveis diferentes - a Lealdade verdadeira quando a atitude é favorável e a recompra é consistente; a Lealdade espúria (falsa) que ocorre quando o cliente compra regularmente (comportamento forte), porém demonstra baixo comprometimento em termos de atitude não possuindo preferência; a Lealdade latente que ocorre quando o cliente, apesar de 
demonstrar atitude forte apresenta baixo nível de recompra; e, por fim, a falta de Lealdade, que ocorre em situações quando os consumidores apresentam um baixo nível de preferência (atitude fraca) e de comportamento (frequência irregular de compras). Segundo os autores, consumidores que apresentam Lealdade espúria, podem estar propensos a substituir o fornecedor em face de melhores alternativas, enquanto consumidores que apresentam Lealdade latente podem estar enfrentando barreiras de acesso ao produto ou ao serviço.

Em mercados com baixa diferenciação entre competidores, como alguns tipos de varejo com alta volatilidade, heterogeneidade de fatores que influenciam a decisão de compra e com grande competitividade de preços, existe clara dificuldade na formação de Lealdade (Dick \& Basú, 1994). Entretanto, os autores ressaltam que, mesmo nestes mercados, o esforço do fornecedor pode provocar uma melhoria na atitude do consumidor, provendo relacionamento que pode resultar na formação da preferência, como contribuição significativa para a manutenção da Lealdade em longo prazo (Dick \& Basú, 1994; Jones \& Sasser, 1995).

Vários autores já citaram diversas variáveis presentes nos relacionamentos que antecedem diretamente a construção da Lealdade dos consumidores, sendo elas: a Satisfação (Dick \& Basú, 1994; Oliver, 1997), a Qualidade percebida (Dabholkar, Thorpe, \& Rentz, 1996; Parasuraman, Zeithaml, \& Berry, 1988) e a Confiança (Garbarino \& Johnson, 1999; Sirdeshmukh, Sing, \& Sabol, 2002). Existem também outros fatores situacionais que diretamente influenciam a construção da Lealdade dos consumidores, como o Valor percebido nas trocas relacionais (Sirdeshmukh et al., 2002) e o Custo de mudança dos consumidores na procura por novos fornecedores (Burnham, Frels, \& Mahajan, 2003). A importância desses antecedentes da Lealdade e as evidências de relacionamento desses construtos com os tipos de Justiça percebida pelos consumidores, após a ocorrência do processo de recuperação de falhas, propiciaram a formulação das hipóteses desta pesquisa.

\section{Formulação das hipóteses}

Visando identificar o relacionamento entre a percepção dos tipos de Justiça e a influência na Satisfação, na Qualidade percebida e na Confiança dos consumidores, propõem-se as hipóteses a seguir:

A Justiça distributiva pode ser traduzida como a equidade percebida do resultado tangível de uma disputa, negociação ou de decisão envolvendo duas ou mais partes em um processo de recuperação de falha (Blodgett et al., 1993). Esta percepção possivelmente influencia o julgamento de Satisfação, Qualidade e Confiança do consumidor em relação ao fornecedor. Daí propõem-se:

H1a - Existe relação positiva entre a Justiça distributiva e a Satisfação do consumidor, em uma situação de recuperação de falha no varejo.

H1b - Existe relação positiva entre a Justiça distributiva e a Qualidade percebida pelo consumidor, em uma situação de recuperação de falha no varejo.

H1c - Existe relação positiva entre a Justiça distributiva e a Confiança do consumidor, em uma situação de recuperação de falha no varejo.

O entendimento da Justiça processual se baseia na percepção dos consumidores após a operação dos processos (Blodgett et al., 1997). Muito provavelmente esta percepção afeta o julgamento de Satisfação, Qualidade percebida e Confiança dos consumidores em relação ao fornecedor. Então:

H2a - Existe relação positiva entre a Justiça processual e a Satisfação do consumidor, em uma situação de recuperação de falha no varejo.

H2b - Existe relação positiva entre a Justiça processual e a Qualidade percebida pelo consumidor, em uma situação de recuperação de falha no varejo. 
H2c - Existe relação positiva entre a Justiça processual e a Confiança do consumidor, em uma situação de recuperação de falha no varejo.

O entendimento dos consumidores sobre a Justiça interpessoal - maneira pela qual foram tratados durante a decorrência do processo de resolução, por exemplo, com cortesia e respeito ou até de forma rude (Bies \& Shapiro, 1987; Tax et al. 1998) -, possivelmente influenciará os consumidores, com isto:

H3a - Existe relação positiva entre a Justiça interpessoal e a Satisfação do consumidor, em uma situação de recuperação de falha no varejo.

H3b - Existe relação positiva entre a Justiça interpessoal e a Qualidade percebida pelo consumidor, em uma situação de recuperação de falha no varejo.

H3c - Existe relação positiva entre a Justiça interpessoal e a Confiança do consumidor, em uma situação de recuperação de falha no varejo.

A Satisfação representa um fator chave no relacionamento de longo prazo entre compradores e fornecedores de serviços, pois, com sua obtenção, o cliente se torna motivado para repetir a compra e recomendar o fornecedor para outros clientes potenciais (Lam, Shankar, Erramilli, \& Murthy, 2004). Após a solução do processo de reclamação e a percepção dos tipos de Justiça, muito possivelmente a Satisfação em relação à sua Lealdade para com o fornecedor de serviços foi alterada. Com isto:

H4 - A Satisfação do consumidor se relaciona positivamente com a Lealdade ao varejista, em uma situação de recuperação de falha no varejo.

A ocorrência de encontros entre consumidores e fornecedores pode reforçar a percepção da qualidade, modificando as futuras intenções de compra dos clientes (Cronin \& Taylor, 1992). Com a percepção dos tipos de Justiça, o consumidor possui entendimentos diferenciados da Qualidade percebida dos fornecedores após a recuperação da falha, afetando, assim, a sua Lealdade. Com isto, é razoável admitir que:

H5 - A Qualidade percebida pelo consumidor se relaciona positivamente com a Lealdade ao varejista, em uma situação de recuperação de falha no varejo.

A Confiança está associada aos riscos que o consumidor encontra ao adquirir serviços de determinado fornecedor (Dowling \& Staelin, 1994). Esse construto possivelmente é influenciado com a percepção de Justiça que os reclamantes têm após a resolução da falha, influenciando a sua Lealdade perante o fornecedor. Então se espera que:

H6 - A Confiança dos consumidores se relaciona positivamente com a Lealdade ao varejista, em uma situação de recuperação de falha no varejo.

Após a recuperação da falha pelo fornecedor de serviços, as posições de Valor e Custos de mudança dos consumidores possivelmente serão modificadas, pois o Valor é definido como a percepção do consumidor dos benefícios menos os Custos de manutenção de um relacionamento contínuo com um fornecedor de serviços (Sirdeshmukh et al., 2002). Após a resolução da falha, possivelmente esse posicionamento perante o fornecedor de serviços será alterado, afetando assim a Lealdade junto ao mesmo. Com isso:

H7 - Em uma situação de recuperação de falha no varejo, quanto maior for o Valor percebido, maior será a Lealdade do consumidor.

Custos de mudança são aqueles a que o consumidor incorre por trocar de fornecedor e que não aconteceriam se o mesmo permanecesse com o fornecedor do momento (Lee, Lee, \& Feick, 2001). Finalizado o processo de recuperação da falha, possivelmente o consumidor terá a sua percepção alterada sob esse aspecto. Então supomos que: 
H8 - Em uma situação de recuperação de recuperação de falha no varejo, quanto maior for o Custo de mudança, maior será a Lealdade do consumidor.

A Lealdade dos consumidores pode ser medida conjuntamente pela repetição do comportamento de compra e pela intenção do consumidor em manter no longo prazo o relacionamento comercial com um fornecedor (Oliver, 1999; Sheth, Mittal, \& Newman, 1999; Sirdeshmukh et al., 2002). Conforme Dick e Basú (1994), é possível entender que esta diferenciação (atitudinal e comportamental) representa uma maneira de desenvolver a capacidade de previsão de recompra, além de proporcionar aos gestores das organizações indicadores para a adoção e o monitoramento das estratégias de retenção de clientes.

A Lealdade atitudinal é a declaração de reutilização, o entendimento do consumidor de que os benefícios desse relacionamento suplantam seus Custos, gerando atitude em recomendar um produto ou serviço para amigos (Sirdeshmukh et al., 2002). Então:

H9 - Em uma situação de recuperação de falha no varejo, existe relação positiva entre as atitudes dos consumidores e a Lealdade com o fornecedor de serviços.

Em relação ao modo comportamental, determinada por indicadores como frequência e volume de compras dos consumidores (Jones \& Sasser, 1995); após o processo de recuperação de falhas, possivelmente o consumidor mudou o seu comportamento em relação ao fornecedor. Então, é necessário verificar se:

H10 - Em uma situação de recuperação de falha no varejo, existe relação positiva entre o comportamento dos consumidores e a Lealdade com o fornecedor de serviços.

Diante das hipóteses sobre as relações entre os construtos que serão analisados, propõem-se, por meio da Figura 1, o modelo conceitual que será testado na etapa empírica deste estudo. Cabe ressaltar que as variáveis latentes foram mensuradas por meio de indicadores reflexivos, pois, como definido pela psicometria, consideram-se reflexivos os indicadores que são explicados pelos construtos (indicadores-efeito), tal como nas escalas de atitude (Babin, Hair, \& Boles, 2008; Chin, 1998, 2010; Coltman, Devinney, Midgley, \& Venaik, 2008), enquanto os indicadores formativos explicam o construto, não sendo esperado que exista correlação entre eles (Coltman et al., 2008; Diamantopoulos \& Siguaw, 2006).

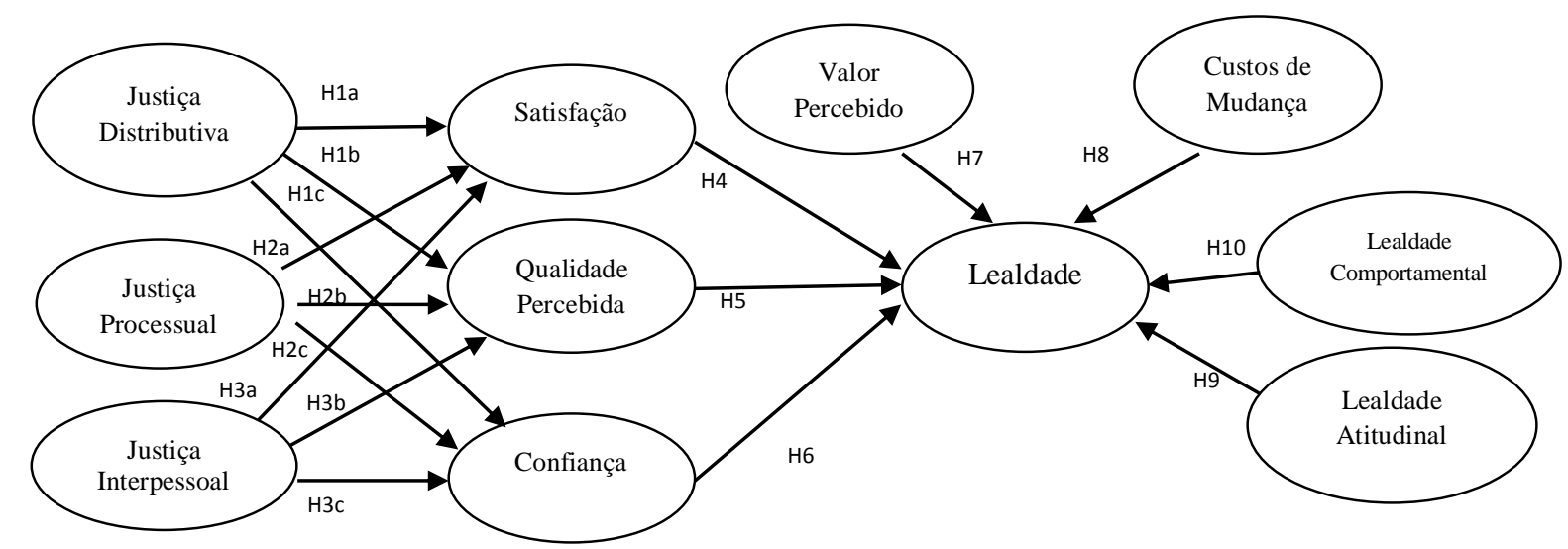

Figura 1. Modelo Conceitual Proposto.

\section{Método}

O estudo empírico realizado pode ser classificado como um survey quantitativo descritivo realizado em corte transversal. 
Como pesquisas antecedentes indicaram a necessidade de se realizar estudos sobre a percepção de Justiça em cenários de recuperação de falha de serviços em ambientes de maior quantidade de concorrentes e menores Custos de mudança (Santos \& Fernandes, 2007), adotou-se como campo de investigação o varejo de materiais de construção. Neste ramo de negócios, a evolução do mercado concorrencial, devido principalmente à entrada de grandes grupos multinacionais, ocasionou a amplitude e a similaridade das operações comerciais (Moriconi, Pacheco, Flório, Tuma, \& Perez, 2006). Essa decisão também encontra respaldo em Lopes, Teixeira e Moretti (2012), que identificaram, no segmento de homecenters, um ambiente varejista de ampla comparabilidade, resultando em baixo custo de mudança para os consumidores.

Utilizou-se o banco de dados que continha informações sobre 4.300 consumidores que acessaram o Serviço de Atendimento ao Cliente (SAC) de um grande varejista nacional, que opera lojas de materiais para construção civil, com o objetivo de registrar uma reclamação sobre uma falha de serviços ocorrida (atrasos ou falta de entrega, produtos recebidos com avarias, falta de produtos disponíveis para compra, problemas com atendimento de funcionários etc.). $\mathrm{O}$ acesso do cliente ao SAC do varejista aconteceu entre 2 e 12 meses antes da data da realização da pesquisa.

\section{Instrumento de coleta de dados}

Utilizou-se um formulário com questões estruturadas. Após a apresentação do entrevistador, solicitava-se que o consumidor indicasse: (a) se lembrava da falha de serviço sofrida; e (b) seu julgamento quanto à solução recebida da sua reclamação por meio de uma escala de 6 pontos (solução excelente, muito boa, boa, ruim, muito ruim e péssima). Em seguida, passava-se para a aplicação das escalas para mensuração dos construtos que formaram o modelo teórico de pesquisa (Justiça distributiva, Justiça processual, Justiça interpessoal, Satisfação, Qualidade percebida, Confiança, Valor percebido e Custo de mudança - e, por fim, os itens para mensuração da Lealdade). Para esta mensuração, foram utilizadas escalas adaptadas de trabalhos anteriores, como descrito na Tabela 1 e no Apêndice.

Tabela 1

\section{Modelo Conceitual Proposto}

\begin{tabular}{lll}
\hline Construto & Escala / Questionário & Fonte \\
\hline $\begin{array}{l}\text { Justiça } \\
\text { Distributiva }\end{array}$ & $\begin{array}{l}\text { 4 itens avaliados por meio de escala de 10 pontos (1 - } \\
\text { Discordo Totalmente e 10 - Concordo totalmente) }\end{array}$ & $\begin{array}{l}\text { Adaptado de Blodgett } \text { et al. (1997), } \\
\text { Tax } \text { et al. (1998); Smith, Bolton e } \\
\text { Wagner (1999). }\end{array}$ \\
\hline Justiça Processual & $\begin{array}{l}5 \text { itens avaliados por meio de escala de 10 pontos (1 - } \\
\text { Discordo Totalmente e 10 - Concordo totalmente) }\end{array}$ & $\begin{array}{l}\text { Adaptado de Blodgett } \text { et al. (1997), } \\
\text { Thibaut e Walker (1975). }\end{array}$ \\
\hline $\begin{array}{l}\text { Justiça } \\
\text { Interpessoal }\end{array}$ & 6 itens avaliados por meio de escala de 10 pontos (1 - & $\begin{array}{l}\text { Adaptado de Clemmer (1988); Tax } \\
\text { et al. } \text { (1998). }\end{array}$ \\
\hline Satisfação & Discordo Totalmente e 10 - Concordo totalmente) & Adaptado de Oliver (1997). \\
\hline Confiança & Discordo Totalmente e 10 - Concordo totalmente) & \\
\hline $\begin{array}{l}\text { Qualidade } \\
\text { percebida }\end{array}$ & Discordo Totalmente e 10 - Concordo totalmente) & $\begin{array}{l}\text { Adaptado de Dowling } e \text { Staelin } \\
\text { (1994). }\end{array}$ \\
\hline Valor percebido & Discordo Totalmente e 10 - Concordo totalmente) & $\begin{array}{l}\text { Adaptado de Dabholkar } \text { et al. } \\
\text { (1996). }\end{array}$ \\
\hline
\end{tabular}




\section{Tabela 1 (continuação)}

\begin{tabular}{lll}
\hline Construto & Escala / Questionário & Fonte \\
\hline Custo de mudança & $\begin{array}{l}\text { 6 itens avaliados por meio de escala de 10 pontos (1 - } \\
\text { Discordo Totalmente e 10 - Concordo totalmente) }\end{array}$ & Adaptado de Lee et al. (2001). \\
\hline $\begin{array}{l}\text { Lealdade } \\
\text { Atitudinal }\end{array}$ & $\begin{array}{l}5 \text { itens avaliados por meio de escala de 10 pontos (1 - } \\
\text { Discordo Totalmente e 10 - Concordo totalmente) }\end{array}$ & Adaptado de Oliver (1997). \\
\hline $\begin{array}{l}\text { Lealdade } \\
\text { Comportamental }\end{array}$ & $\begin{array}{l}\text { 2 itens declarados (Quantidade de visitas realizadas ao } \\
\text { varejista nos últimos 3 meses e percentual do gasto } \\
\text { realizado em compras no varejista em comparação ao } \\
\text { gasto total) }\end{array}$ & Adaptado de Lopes (2007). \\
\hline
\end{tabular}

\section{Amostra, procedimentos de campo e plano de análise dos dados}

Para o preenchimento dos questionários, utilizou-se a estratégia de entrevistas por telefone, realizadas por seis entrevistadores especialmente treinados para essa tarefa.

Sorteou-se aleatoriamente $25 \%$ dos sujeitos constantes no banco de dados $(n=1.075)$, o que permite classificar a amostra como probabilística. As ligações telefônicas foram realizadas em dias úteis, no horário comercial, durante os meses de janeiro e fevereiro de 2011. Após as ligações realizadas, contabilizaram-se $604(56,1 \%)$ consumidores que se disponibilizaram a responder o questionário.

Para a análise dos relacionamentos entre os construtos, escolheu-se a técnica de Modelagem de Equações Estruturais (MEE), com a análise prévia das observações atípicas (outliers), tratamento da colinearidade e a verificação da normalidade para suportar a decisão entre a utilização da análise por meio do LISREL e ou do modelo PLS.

\section{Resultados Observados}

O objetivo deste capítulo é apresentar os resultados da pesquisa empírica.

\section{Preparação prévia dos dados e perfil dos respondentes}

Na preparação do banco de dados para as análises uni e multivariadas propostas neste estudo, foram descartados 92 questionários, sendo 7 por missing values e 85 em que os respondentes demonstraram evidente descontentamento em relação à solução recebida da sua reclamação ao varejista (avaliação ruim, muito ruim ou péssima na pergunta filtro). Esse fenômeno demonstra assimetria entre o entendimento da empresa e a opinião dos consumidores. Assim, o banco de dados passou a contar com 512 observações. Deste total, 238 são mulheres $(46,49 \%)$ e 274 homens $(53,51 \%)$, com idade média de 43 anos e com escolaridade variando entre o ensino superior completo $(47 \%)$ e o ensino médio $(41 \%)$. Quanto à profissão dos respondentes, existiu grande variância, sendo esta caracterizada pelo baixo índice de compradores profissionais, comuns ao setor pesquisado (arquitetos, construtores, carpinteiros, decoradores e engenheiros), e uma grande incidência de consumidores finais (aquele consumidor que adquire produtos para o seu próprio uso).

\section{Análises preliminares do banco de dados}

A identificação de outliers univariados deu-se pela análise do gráfico boxplot e a identificação dos outliers multivariados deu-se pela análise da distância de Mahalanobis (Hair, Anderson, Tatham, \& Black, 2005), resultando na eliminação de 29 observações atípicas. 
A ausência de multicolinearidade foi identificada por meio da análise do índice de inflação da variância $(\mathrm{VIF}<10)$, e a normalidade da distribuição dos dados foi verificada por meio do teste de KSKolmogorov-Smirnov (Hair et al., 2005). O teste KS é o alternativo ao teste W de Shapiro para variáveis oriundas de amostras superiores a 30 observações, e compara a distribuição amostral à curva de Gauss (Field, 2009; Hair et al., 2005).

Esta última análise indicou que a distribuição das variáveis dependentes do modelo teórico (Satisfação, Qualidade percebida, Confiança e Lealdade) não possuía normalidade multivariada. Diante disso, decidiu-se pela MEE por meio da matriz de correlação (Chin \& Newsted, 1999) e pelo método de estimação de Mínimos Quadrados Parciais, também conhecido como Partial Least Square Path Modeling (PLS-PM), com utilização do software estatístico Smart PLS 2.0 M. A regressão por Mínimos Quadrados Parciais é uma técnica de análise de dados multivariados utilizada para relacionar uma ou mais variáveis resposta (dependentes) com diversas variáveis independentes (Babin et al., 2008), baseada no uso de fatores (combinações lineares das variáveis dependentes). A técnica permite identificar as regressões que melhor expliquem as variáveis dependentes (Babin et al., 2008; Cassel, Hackl, \& Westlund, 1999). Além disso, admite, com eficiência, trabalhar com conjuntos de dados nos quais haja variáveis altamente correlacionadas e que apresentem ruído aleatório considerável (Diamantopoulos \& Siguaw, 2006), além de ser adequada para estimação de modelos cujas variáveis não atendem ao princípio da normalidade multivariada (Chin, 2010).

Outra característica importante da estimação por Mínimos Quadrados Parciais é que ela estima os escores das variáveis latentes, como combinações lineares exatas das suas variáveis manifestas associadas. Com isso, é possível identificar a variância que é útil para explicar a(s) variável(is) latente(s) endógena(s). Hair, Sarstedt, Ringle e Mena (2012) reforçam ainda que as regressões do PLS não dispensam a suposição de normalidade multivariada necessária para as estimativas baseadas em máxima verossimilhança (maximum likelihood).

\section{Validade convergente}

Para Chin (1998), a validade convergente é obtida quando se verificam cargas superiores a 0,50 entre os itens e os construtos. Na primeira tentativa de estabelecer a validade convergente, buscou-se também identificar outros índices de ajustamento (Análise da variância extraída [AVE], Confiabilidade composta, Coeficiente de determinação $\left(\mathrm{R}^{2}\right)$, Alfa de Cronbach, Comunalidade e Redundância). Os primeiros resultados indicaram a necessidade de retirar 5 variáveis com cargas abaixo de 0,5\% ( 1 item do Custo Mudança, 2 itens de Qualidade e 2 itens de Valor).

Após a eliminação dessas variáveis, os itens passaram a apresentar cargas adequadas $(>0,50)$ e os indicadores foram satisfatórios, como apresentado na Tabela 2.

Tabela 2

Verificação da Validade Convergente

\begin{tabular}{lcccccc}
\hline Construtos & AVE & $\begin{array}{c}\text { Confiabilidade } \\
\text { de composição }\end{array}$ & $\mathbf{R}^{\mathbf{2}}$ & $\begin{array}{c}\text { Alfa de } \\
\text { Cronbach }\end{array}$ & Comunalidade & Redundância \\
\hline Custo de mudança & 0,59 & 0,88 & & 0,82 & 0,59 & \\
Confiança & 0,67 & 0,89 & 0,55 & 0,84 & 0,67 & 0,18 \\
Justiça distributiva & 0,78 & 0,93 & & 0,91 & 0,78 & \\
Justiça interpessoal & 0,68 & 0,93 & & 0,91 & 0,68 & \\
Justiça processual & 0,68 & 0,92 & & 0,88 & 0,68 & \\
Lealdade & 0,67 & 0,93 & 0,70 & 0,92 & 0,67 & 0,16 \\
\hline
\end{tabular}


Tabela 2 (continuação)

\begin{tabular}{lcccccc}
\hline Construtos & AVE & $\begin{array}{c}\text { Confiabilidade } \\
\text { de composição }\end{array}$ & $\mathbf{R}^{2}$ & $\begin{array}{c}\text { Alfa de } \\
\text { Cronbach }\end{array}$ & Comunalidade & Redundância \\
\hline Qualidade & 0,52 & 0,81 & 0,47 & 0,69 & 0,52 & 0,12 \\
Satisfação & 0,75 & 0,94 & 0,61 & 0,92 & 0,75 & 0,31 \\
Valor & 0,55 & 0,83 & & 0,72 & 0,55 & \\
\hline
\end{tabular}

Nota. Valores de referência segundo Chin, W.W, (1998). The partial least squares approach for structural equation modeling. In G. A. Marcoulides (Ed.), Moderns methods for business research. Methodology for business and management (pp. 295336). Mahwah, NJ, US: Lawrence Erlbaum Associates Publishers - AVE, Confiabilidade e Comunalidade $>0,50$, Alfa de Cronbach $>0,60$, Redundância $<0,50$.

\section{Validade discriminante}

A análise da validade discriminante consiste no grau em que dois conceitos similares são distintos (Hair et al., 2005). Assim, o teste empírico avalia a correlação entre as medidas, considerando se a escala múltipla está correlacionada com medidas semelhantes, porém conceitualmente distintas. O ideal, segundo essa abordagem, é encontrar valores baixos entre essas correlações.

Esse critério supõe que, na existência da validade discriminante, as variáveis do construto exercem maior poder de explicação para aquele construto do que para outro do modelo (Chin, 1998). Portanto, a raiz quadrada da AVE do construto deve ser superior à correlação deste com os demais. Na primeira análise, a raiz quadrada da AVE do construto Satisfação $(0,724)$ era menor que a correlação de Satisfação com Qualidade percebida $(0,726)$.

Identificou-se, por meio da análise da matriz de correlações bivariada, que o coeficiente de correlação de Spearman dos itens Sat4 e Qper5 era superior a 0,50 $(0,56)$ e, portanto, um dos itens deveria ser eliminado do modelo. Como no construto Qualidade percebida já haviam sido eliminadas duas variáveis (Qper1 e Qper2) na etapa de validação convergente, decidiu-se pela remoção da variável da Satisfação (Sat4).

Após o descarte da variável (Sat4) que apresentava carga correlacionada entre os construtos Satisfação e Qualidade percebidos, ocorreu nova verificação da validade discriminante. Os índices encontrados nessa tentativa apresentaram resultados aceitáveis (Chin, 1998), como demonstrado na Tabela 3.

Tabela 3

Validade Discriminante do Modelo

\begin{tabular}{|c|c|c|c|c|c|c|c|c|c|}
\hline Construtos & $\begin{array}{l}\text { Custo de } \\
\text { Mudança }\end{array}$ & Confiança & $\begin{array}{c}\text { Justiça } \\
\text { Distributiva }\end{array}$ & $\begin{array}{c}\text { Justiça } \\
\text { Interpessoal }\end{array}$ & $\begin{array}{c}\text { Justiça } \\
\text { Processual }\end{array}$ & Lealdade & Qualidade & Satisfação & Valor \\
\hline $\begin{array}{l}\text { Custo de } \\
\text { Mudança }\end{array}$ & 0,765 & & & & & & & & \\
\hline Confiança & 0,563 & 0,821 & & & & & & & \\
\hline $\begin{array}{l}\text { Justiça } \\
\text { Distributiva }\end{array}$ & 0,530 & 0,648 & 0,883 & & & & & & \\
\hline $\begin{array}{l}\text { Justiça } \\
\text { Interpessoal }\end{array}$ & 0,467 & 0,707 & 0,700 & 0,826 & & & & & \\
\hline $\begin{array}{l}\text { Justiça } \\
\text { Processual }\end{array}$ & 0,455 & 0,609 & 0,737 & 0,732 & 0,827 & & & & \\
\hline
\end{tabular}


Tabela 3 (continuação)

\begin{tabular}{|c|c|c|c|c|c|c|c|c|c|}
\hline Construtos & $\begin{array}{l}\text { Custo de } \\
\text { Mudança }\end{array}$ & Confiança & $\begin{array}{c}\text { Justiça } \\
\text { Distributiva }\end{array}$ & $\begin{array}{c}\text { Justiça } \\
\text { Interpessoal }\end{array}$ & $\begin{array}{c}\text { Justiça } \\
\text { Processual }\end{array}$ & Lealdade & Qualidade & Satisfação & Valor \\
\hline Lealdade & 0,662 & 0,682 & 0,661 & 0,578 & 0,590 & 0,820 & & & \\
\hline Qualidade & 0,494 & 0,711 & 0,610 & 0,640 & 0,604 & 0,609 & 0,724 & & \\
\hline Satisfação & 0,529 & 0,796 & 0,726 & 0,702 & 0,681 & 0,756 & 0,711 & 0,875 & \\
\hline Valor & 0,674 & 0,528 & 0,639 & 0,473 & 0,571 & 0,696 & 0,495 & 0,622 & 0,744 \\
\hline
\end{tabular}

Nota. A diagonal em destaque indica a raiz quadrada da AVE do construto.

\section{Análise dos caminhos}

Após as validações convergente e discriminante realizou-se a MEE com a respectiva análise dos caminhos. A Figura 2 retrata esse resultado.

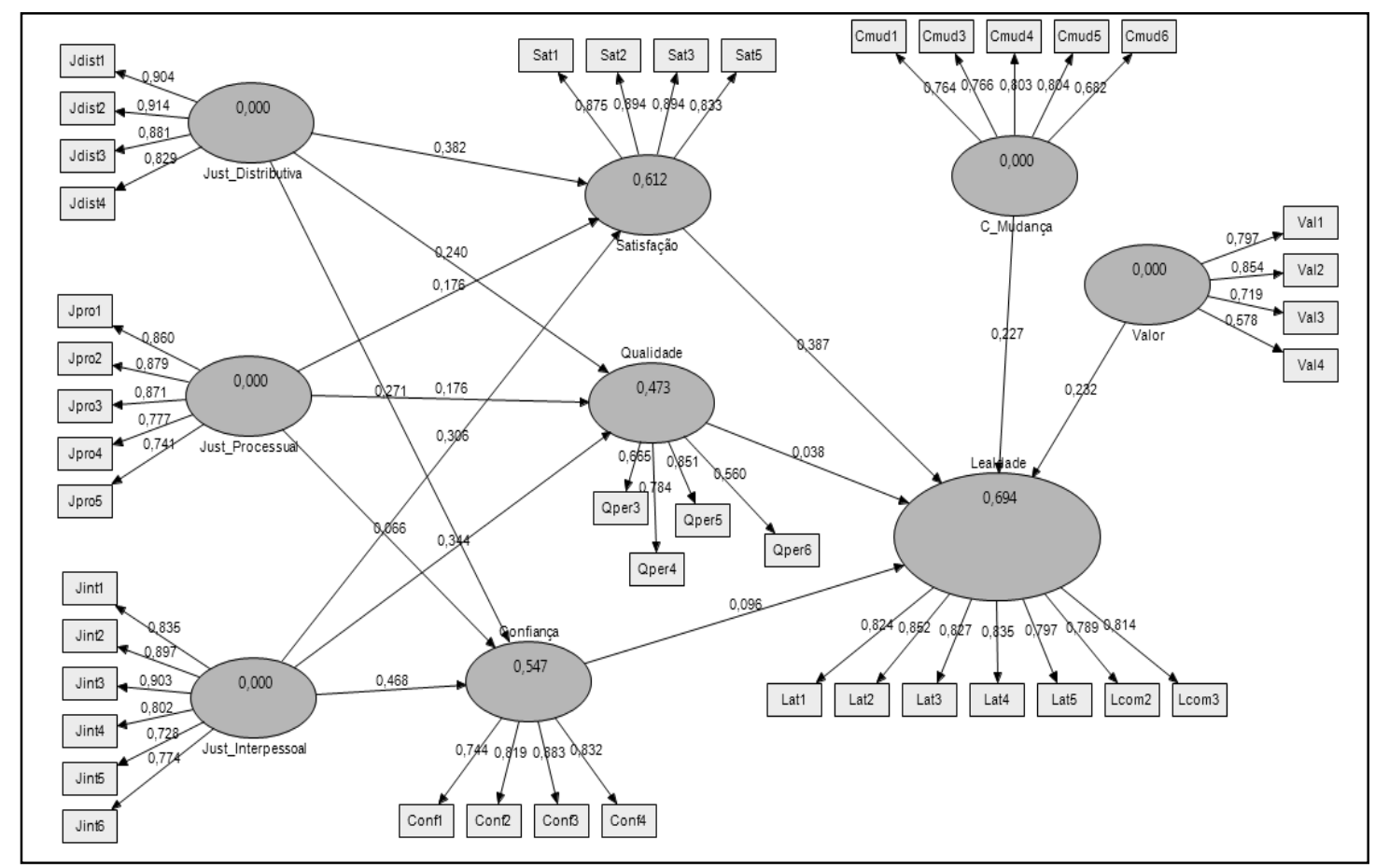

Figura 2. Modelo Estrutural.

Como pode ser visto, todos os caminhos entre os construtos apresentaram cargas positivas e o $\mathrm{R}^{2}$ da Lealdade foi elevado $(0,694)$. Contudo, algumas cargas fatoriais foram baixas indicando a necessidade da verificação da significância dos relacionamentos, o que foi realizado por meio do bootstrapping.

A técnica do bootstrapping é uma forma de reamostragem na qual os dados originais são repetidamente amostrados com substituição para a estimação do modelo (Hair et al., 2005). Neste estudo, optou-se pela utilização de 200 casos com 300 repetições, para a verificação do teste $t$ (Student) (Hair et al. 2005). O teste $t$ avalia a significância estatística da diferença entre duas médias de amostras independentes ou, em outras palavras, o valor de $t$ representa a diferença de grupos em termos de erro padrão. Se esse valor é grande o suficiente, então, estatisticamente, pode-se dizer que a diferença não era devida à variabilidade da amostra, mas que representa uma diferença verdadeira. 


\section{Teste das hipóteses}

A análise do teste $t$ dos caminhos identificou cinco relações que estiveram abaixo dos Valores críticos adotados no estudo, e foram considerados como não significantes. A Tabela 4 apresenta esses resultados.

Tabela 4

Teste das Hipóteses

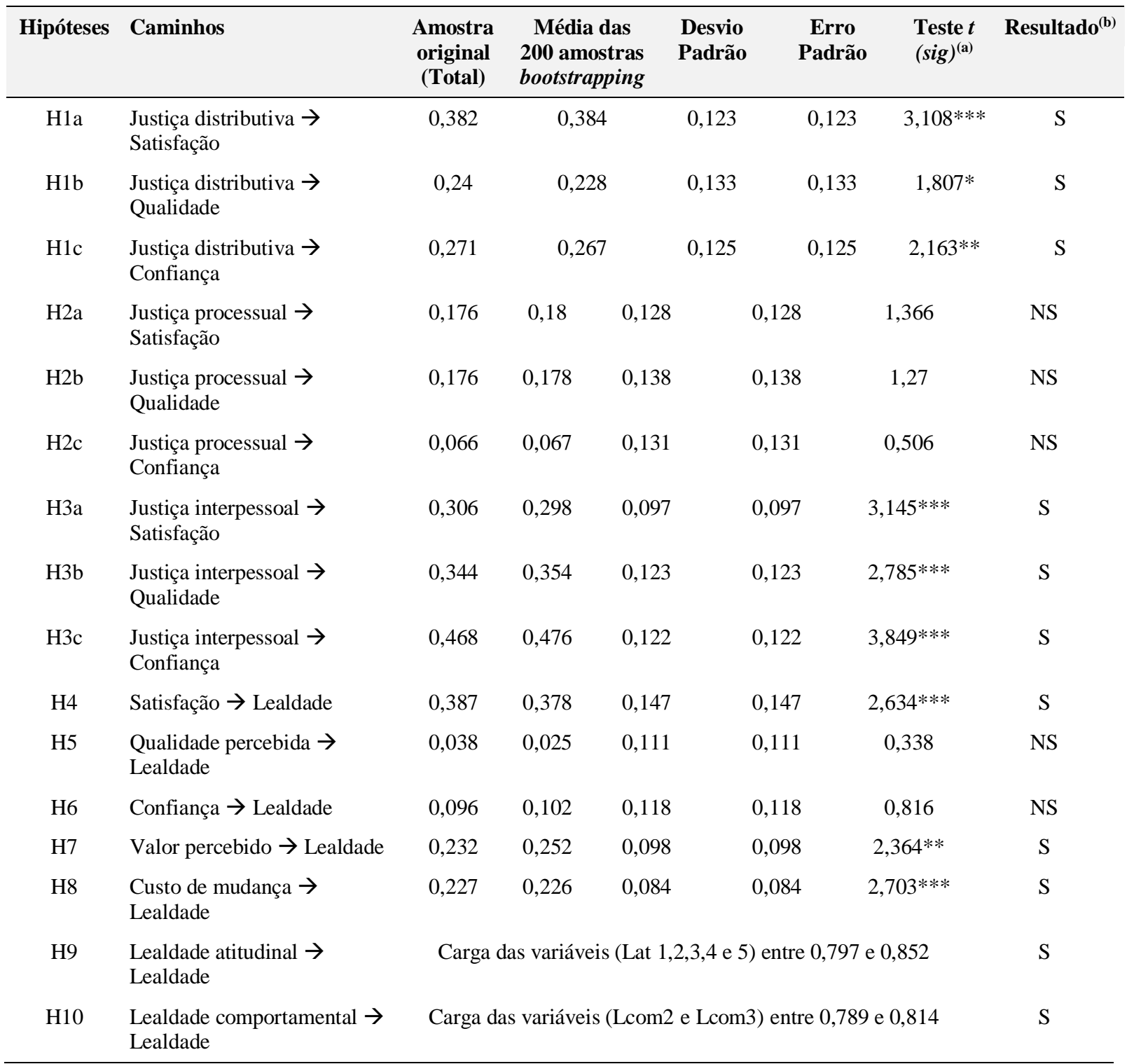

Nota. (a) Os valores críticos para t (199g.1.): *p<10\%=1,653; **p<5\%=1,972 e ***p<1\%=2,601; (b) "S"= Hipótese suportada pelos dados empíricos "NS"=Hipótese não suportada pelos dados empíricos.

\section{Discussão dos Resultados Observados e Considerações Finais}

Como se esperava, existe relacionamento positivo entre a Justiça distributiva e a Justiça Interpessoal e os antecedentes da Lealdade (Qualidade Percebida, Satisfação e Confiança). Porém, ao contrário do que se previa, não se observou relacionamento significante entre a Justiça processual e os 
antecedentes da Lealdade, corroborando parcialmente estudos anteriores que também não identificaram influência entre a Justiça processual e a Satisfação (Matos \& Leis, 2013). Esse fenômeno pode estar ligado ao fato de que os consumidores, apesar de perceberem que não foram lesados financeiramente, por entenderem o resultado da recuperação da falha como equitativo e também terem a percepção de que o atendimento prestado pelos funcionários do varejista foi adequado, o processo vivido para fazer a reclamação da falha e, posteriormente, tê-la solucionada, foi desgastante e moroso. Isso pode estar ligado ao procedimento operacional do varejista estudado, que se utiliza de frota de veículos terceirizada e, em grande parte, depende desse serviço para realizar a substituição de produtos defeituosos entregues. Do mesmo modo, o varejista não tem controle absoluto do leadtime das entregas.

De forma geral, o resultado encontrado nesta aplicação se contrapõe ao observado por Tax et al. (1998). Naquele estudo, os autores ressaltam que muitos consumidores, mesmo percebendo a reparação da falha de serviço, não demonstram haver percebido Justiça Distributiva e Interpessoal e que, quando uma falha ocorre, o sentimento de justiça não é reparado rapidamente.

A relação entre os antecedentes da Lealdade e a Lealdade dos consumidores no processo de recuperação de falhas foi testada pelas hipóteses, H4, H5 e H6. Nesta análise, o relacionamento entre a Satisfação e a Lealdade (H4) foi o único positivo e significativo. Mesmo que a Justiça Processual não tenha colaborado na formação da Satisfação, este resultado não chega a surpreender. $O$ estudo de Blodgett, Hill e Tax (1997) identificou que o modo como os consumidores são tratados (Justiça interpessoal) exerce uma maior influência na Satisfação do que posicionamentos negativos relativos aos processos. Também o estudo de Martinez-Tur et al. (2006) identificou a superioridade da percepção de Justiça distributiva em predizer a Satisfação do consumidor.

Um achado deste estudo é o não relacionamento positivo entre Qualidade Percebida e a Lealdade e entre Confiança e a Lealdade no cenário de recuperação de falhas de serviço. Se por um lado, identificou-se que o consumidor percebeu Justiça Distributiva e Interpessoal e, com isso, ficou satisfeito com o desfecho de seu caso; por outro, a falha ocorrida afetou a sua percepção de Qualidade e de Confiança que não explicaram a Lealdade da amostra. Fica então um alerta aos operadores varejistas: mesmo que a recuperação da falha ocorra, a imagem de Qualidade operacional/comercial e a Confiança na instituição podem ficar abaladas por um período maior do que se imaginava.

Em um estudo anterior, Blodgett et al. (1997), que simularam processos de recuperação de falhas em uma loja de sapatos do varejo americano, identificaram que, nos cenários nos quais o processo de recuperação foi facilitado e a solução da falha ocorreu de forma simples, os consumidores externaram alto nível de Confiança no varejista. Entretanto, a Confiança dos consumidores foi afetada negativamente quando a solução foi retardada por falta do produto substituto, erro nos prazos ou dificuldade encontrada pelo consumidor para reclamar. Como a Justiça processual não foi percebida neste estudo, existe também a possibilidade de que, como no julgamento do consumidor, o processo para recuperação da falha não foi adequado, houve comprometimento da Confiança no varejista.

As hipóteses destinadas a verificar a relação entre o Valor percebido (H7) e o Custo de mudança (H8) com a Lealdade dos consumidores foram suportadas. O Valor percebido pelos respondentes da pesquisa foi principalmente representado pela vantagem de tempo que os mesmos entendem encontrar ao realizarem as suas compras no fornecedor e nas vantagens que possuem em adquirir os diversos serviços desse varejista em detrimento aos demais concorrentes do setor. Este fato pode ser entendido como uma posição de destaque do fornecedor em relação à concorrência. Tal resultado corrobora o entendimento de Lam, Shankar, Erramilli e Murthy (2004), que afirmam que os consumidores podem permanecer leais se sentirem que estão recebendo um maior valor de uma determinada empresa em relação a seus concorrentes.

A confirmação da hipótese sobre o Custo de mudança, considerando que quanto maior for o Custo de mudança maior será a Lealdade do consumidor, pode ser explicada pelo reconhecimento que os consumidores externaram sobre a preocupação com o tempo necessário para adaptação a um novo fornecedor de produtos. Mesmo que os respondentes tenham concordado que existem várias lojas nas 
quais poderiam se abastecer, a maioria considerou a existência de dificuldade de adaptação a outro fornecedor, e o quanto isso seria complicado, o que pode ser verificado pelo julgamento de valor e pelos benefícios que entenderam ter com os serviços do varejista. Esse posicionamento resulta na construção de barreiras de saída, ocasionando possivelmente a Lealdade desses consumidores. Burnham, Frels e Mahajan (2003) contribuem para esse entendimento, quando afirmam que os clientes podem não trocar de fornecedor por terem um Custo de mudança alto ou difícil de ser compreendido devido à dificuldade de informações propiciada pelo setor ou pelo custo de avaliação que a troca lhe causaria diante dos benefícios perdidos.

As hipóteses que verificaram a relação positiva entre a Lealdade atitudinal (H9) e a Lealdade comportamental dos consumidores (H10) com a Lealdade, também foram suportadas. Esse resultado positivo de relacionamento reforça o conceito bidimensional da Lealdade, apresentado por Dick e Basú (1994).

\section{Considerações finais}

Os resultados encontrados no teste das hipóteses permitem que se afirme que o modelo teórico proposto é robusto para o fim a que se propõe. Com a análise dos caminhos e a confirmação (ou não) das hipóteses testadas, foi possível identificar as relações sugeridas no estudo, como a percepção dos diversos julgamentos da Justiça pelos consumidores reclamantes e a identificação específica da influência da percepção da Justiça na Satisfação, na Qualidade percebida e na Confiança.

Acredita-se que se tenha respondido a questão de pesquisa formulada (qual a influência da Justiça nos antecedentes da Lealdade dos consumidores após um processo de recuperação de falhas no varejo?), pois se identificou a relação entre a Justiça, em sua composição tridimensional, e os antecedentes da Lealdade.

A importância dos resultados encontrados encontra amparo acadêmico na afirmação de Blodgett et al. (1995), em que varejistas e prestadores de serviço podem visualizar o processo de comportamento dos reclamantes como uma importante oportunidade de solidificar e fortalecer os relacionamentos com os seus clientes.

\section{Contribuições acadêmicas}

O presente estudo diferencia-se dos realizados por Santos e Fernandes (2008), principalmente por ser realizada em ramo do comércio que possui baixas barreiras à saída dos consumidores e pela utilização de banco de dados real, oriundo de uma grande empresa de varejo de materiais de construção. Com isto, este estudo analisou uma situação real de processos de recuperação de falha. A segunda contribuição foi identificar a relação da Justiça percebida com os antecedentes da Lealdade, e entender como estes antecedentes explicam a Lealdade dos consumidores.

A terceira contribuição foi promover a análise agregada: em um único modelo, vários construtos que são considerados antecedentes de forte relevância na construção da Lealdade dos consumidores. O estudo da Satisfação, da Qualidade, da Confiança, do Valor percebido e do Custo de mudança dos consumidores são temas que, apesar de já bastante explorados, são extremamente importantes para o entendimento da influência da gestão relacional com consumidores, o que per si, já justifica a continuidade de trabalhos acadêmicos nesta linha temática.

\section{Contribuições gerenciais}

A alta competitividade e a busca por diferenciação neste tipo de varejo induz as organizações a uma preocupação constante com fatores que proporcionem a retenção dos consumidores. O modelo teórico analisado propicia aos gestores a identificação de pontos nevrálgicos do processo de recuperação de falhas que estejam atuando como barreiras ao processo de construção da Lealdade com os seus consumidores. 
De forma operacional, uma indicação deste estudo é a necessidade de se fazer corretamente da primeira vez, sob o risco de comprometer a imagem de Qualidade e a Confiança da carteira de clientes, mesmo que se promovam esforços no sentido de corrigir falhas. Outra contribuição é a constituição de uma ferramenta de pesquisa simples e adequada para se verificar a percepção de Justiça e sua influência na Satisfação, na Qualidade percebida e na Confiança.

Cabe aos gestores do varejo identificar como as suas ações de recuperação de falhas se assemelham às características deste estudo, de forma a minimizar as influências negativas que afetam os antecedentes da Lealdade dos consumidores.

\section{Limitações da pesquisa e contribuições para futuros estudos}

A capacidade de desenvolvimento de um tema tão complexo impõe algumas limitações que servem como barreiras a serem superadas em futuras investigações.

O perfil da amostra constitui a primeira limitação. Mesmo que se tenha conseguido uma amostra probabilística, ela não pode ser classificada como representativa, pois as características específicas dos consumidores do operador varejista analisado podem não encontrar generalização em outras amostras.

A segunda limitação é o corte temporal transversal. Seria muito interessante verificar, com a continuidade do relacionamento entre varejista e consumidor, qual a influência do tempo na percepção de Qualidade e na Confiança. Sugere-se que, na sequência desta linha temática, estudos subsequentes tenham estas preocupações.

Assume-se ainda que um dos limites deste estudo está ligado à sua característica psicométrica. O tripé confiabilidade - consistência interna - validação deve ser observado como forma de não comprometer a fidedignidade das escalas de mensuração e do modelo teórico proposto. Neste estudo, optou-se pela utilização de escalas já validadas em pesquisas anteriores, além da verificação das validades convergente e discriminante. Para a consistência interna, adotaram-se a identificação e a análise do coeficiente de Alfa de Cronbach. Contudo, a confiabilidade, definida como sendo sua capacidade em reproduzir um resultado de forma consistente no espaço e no tempo, ou ainda, com observadores diferentes (Babin et al., 2008; Field, 2009), ficou comprometida. Com isso, recomendase a replicação deste estudo em outras amostras, visando a repetição de sua mensuração e comparação dos resultados obtidos.

Certamente, este estudo não teve a pretensão de esgotar um tema tão complexo e relevante. Apenas teve como missão contribuir, mesmo que minimamente, para o entendimento das consequências dos processos de recuperação de falhas em serviços.

\section{Referências}

Babin, B. J., Hair, J. F., \& Boles, J. S. (2008). Publishing research in marketing journals using structural equation modeling. Journal of Marketing Theory \& Practice, 16(4), 279-285. doi: 10.2753/MTP1069-6679160401

Berry, L., \& Parasuraman, A. (1991). Marketing services: competing through quality. New York, NY: The Free Press.

Bies, R., \& Shapiro, D. (1987). Interactional fairness judgments: the influence of causal Accounts. Social Justice Research, 1(2), 199-218. doi: 10.1007/BF01048016 
Blodgett, J. G., Granbois, D. H., \& Walters, R. G. (1993). The effects of perceived justice on complainants' negative word-of-mouth behavior and repatronage intentions. Journal of Retailing, 69(4), 399-428. doi: 10.1016/0022-4359(93)90015-B

Blodgett, J. G., Hill, D. J., \& Tax, S. S. (1997). The effects of distributive, procedural, and interactional justice on postcomplaint behavior. $J$. Retailing, 73(2), 185-210. doi: 10.1016/S0022-4359(97)90003-8

Blodgett, J. G., Wakefield, K. L., \& Barnes, J. H. (1995). The effects of customer service on consumer complaining behavior. The Journal of Services Marketing, 9(4), 31-42. doi: $10.1108 / 08876049510094487$

Burnham, T. A., Frels, J. K., \& Mahajan, V. (2003). Consumer switching costs: a typology, antecedents and consequences. Journal of the Academy of Marketing Science, 31(2), 109-126. doi: 10.1177/0092070302250897

Cassel, C., Hackl, P., \& Westlund, A. H. (1999). Robustness of partial least-squares method for estimating latent variable quality structures. Journal of Applied Statistics, 26(4), 435-446. doi: $10.1080 / 02664769922322$

Chin, W. W. (1998). The partial least squares approach for structural equation modeling. In G. A. Marcoulides (Ed.), Moderns methods for business research. Methodology for business and management (pp. 295-336). Mahwah, NJ, US: Lawrence Erlbaum Associates Publishers

Chin, W. W. (2010). How to write up and report PLS analyses. In V. E. Vinzi, W. W. Chin, J. Henseler, \& H. Wang (Eds.), Handbook of partial least squares: concepts, methods and applications in marketing and related fields (pp. 655-690). Berlin: Springer.

Chin, W. W., \& Newsted, P. R. (1999). Structural equation modeling analysis with small sample partial least squares. In R. H. Hoyle (Ed.), Statistical strategies for small sample research (pp. 307-341). Thousand Oaks: Sage.

Clemmer, E. C. (1988). The role of fairness in customer satisfaction with services (Doctoral thesis). University of Maryland, Maryland, USA.

Coltman, T., Devinney, T. M., Midgley, D. F., \& Venaik, S. (2008). Formative versus reflective measurement models: two applications of formative measurement. Journal of Business Research, 61(12), 1250-1262. doi: 1016/j.jbusres.2008.01.013

Cronin, J. J., Jr., \& Taylor, S. A. (1992). Measuring service quality: a reexamination and extension. Journal of Marketing, 56(3), 55-68.

Dabholkar, P. A., Thorpe, D. I., \& Rentz, J. O. (1996). A measure of service quality for retail stores: scale development and validation. Journal of the Academy of Marketing Science, 24(1), 3-16. doi: 10.1007/BF02893933

Diamantopoulos, A., \& Siguaw, J. A. (2006). Formative versus reflective indicators in organizational measure development: a comparison and empirical illustration. British Journal of Management, 17(4), 263-282. doi: 10.1111/j.1467-8551.2006.00500.x

Dick, A., \& Basu, K. (1994). Customer loyalty: toward an integrated conceptual framework. Journal of the Academy of Marketing Science, 22(2), 99-113. doi: 10.1177/0092070394222001

Dowling, G. R., \& Staelin, R. (1994). A model of perceived risk and intended risk-handling activity. Journal of Consumer Research, 21(1), 119-134. doi: 10.1086/209386

Field, A. (2009). Descobrindo a estatística usando SPSS (2a ed., P. Lorí Viali, Trad.). Alegre: Artmed. (Obra original publicada em 2005) 
Garbarino, E., \& Johnson, M. (1999). The different roles of satisfaction, trust and commitment for relational and transactional consumers. Journal of Marketing, 63(2), 70-87.

Hair, J. F., Anderson, R. E., Tatham, R. L., \& Black, W. C. (2005). Análise multivariada de dados. Porto Alegre: Bookman.

Hair, J. F., Sarstedt, M., Ringle, C. M., \& Mena, J. A. (2012). An assessment of the use of partial least squares structural equation modeling in marketing research. Journal of the Academy of Marketing Science, 40(3), 414-433. doi: 10.1007/s11747-011-0261-6

Hess, R. L., Ganessan, S., \& Klein, N. M. (2003). Service failure and recovery: the impact of relationship factors on satisfaction. Journal of the Academy of Marketing Science, 31(2), 127145. doi: 10.1177/0092070302250898

Jones, T. O., \& Sasser, W. E. (1995). Why satisfied customers defect. Harvard Business Review, 73(6), 88-99.

Lam, S. Y., Shankar, V., Erramilli, M. K., \& Murthy, B. (2004). Customer value, satisfaction, loyalty, and switching costs: an illustration from a business-to-business service context. Journal of the Academy of Marketing Science, 32(3), 293-311. doi: 10.1177/0092070304263330

Lee, J., Lee, J., \& Feick, L. (2001). The impact of switching costs on the customer satisfaction-loyalty link: mobile phone service in France. The Journal of Services Marketing, 15(1), 35-48. doi: $10.1108 / 08876040110381463$

Lin, H.-H., Wang, Y.-S., \& Chang, L.-K. (2011). Consumer responses to online retailer's service recovery after a service failure: a perspective of justice theory. Managing Service Quality, 21(5), 511-534. doi: 10.1108/09604521111159807

Lopes, E. L. (2007). Avaliação do impacto da qualidade de serviços na lealdade dos consumidores de materiais para construção civil: aplicação dos modelos Servqual e RSQ em homecenters Paulistanos (Dissertação de mestrado). Universidade Nove de Julho, São Paulo, SP, Brasil.

Lopes, E. L., Teixeira, J. M., \& Moretti, S. L. A. do (2012). Valor de compra hedônico ou utilitário e sua influência no varejo: resultados de um survey no setor de construção civil. Organizações \& Sociedade, 19(60), 109-124. doi: 10.1590/S1984-92302012000100006

Magnini, V. P., Ford, J. B., Markowski, E. P., \& Honeycutt, E. D., Jr. (2007). The service recovery paradox: justifiable theory or smoldering myth? Journal Service Marketing, 21(3), 213-225. doi: $10.1108 / 08876040710746561$

Martinez-Tur, V., Peiró, J. M., Ramos, J., \& Moliner, C. (2006). Justice perceptions as predictors of customer satisfaction: the impact of distributive, procedural, and interactional justice. Journal of Applied Social Psychology, 36(1), 100-119. doi: 10.1111/j.0021-9029.2006.00005.x

Matos, C. A., \& Leis, R. P. (2013). The antecedents of complaint behaviour for Brazilian and French consumers of services. International Journal of Consumer Studies, 37(3), 327-336. doi: 10.1111/ijcs.12002

Maxham, J. G., \& Netemeyer, R. G. (2002). A longitudinal study of complaining customer's evaluations of multiple service failures and recovery efforts. Journal of Marketing, 66(4), 5771.

Moriconi, C., Jr., Pacheco, F. A., Flório, M. T., Tuma, R. L., \& Perez, T. H. (2006). Prevenção de perdas no varejo de materiais para construção civil. In J. R. Oliveira Filho (Org.), O varejo de material de construção no Brasil - mecanismos operacionais (Cap. 2. pp. 34-52). São Paulo: Ed. DVS. 
Oliver, R. (1997). Satisfaction: a behavioral perspective on the consumer. Boston, MA: McGrawHill/Irwin.

Oliver, R. (1999). Whence consumer loyalty? (Special Issue). Journal of Marketing, 63, 33-44. doi: $10.2307 / 1252099$

Parasuraman, A., Zeithaml, V. A., \& Berry, L. L. (1988). SERVQUAL: a multiple-item, scale for measuring consumer perceptions of service quality. Journal of Retailing, 64(1), 12-40.

Parente, J. (2000). Varejo no Brasil (2a ed.). São Paulo: Atlas.

Parvatiyar, A., \& Sheth, J. (2000). The domain and conceptual foundations of relationship marketing. In J. Sheth \& A. Parvatiyar (Eds.), Handbook of relationship marketing (pp. 1-49).Thousand OAKS, CA: Sage.

Reichheld, F. F., \& Sasser, W. E., Jr. (1990). Zero defections: quality comes to services. Harvard Business Review, 68(5), 105-111.

Santos, C. P. dos, \& Fernandes, D. H. Von der (2007). A recuperação de serviços e seu efeito na confiança e lealdade do cliente. RAC-Eletrônica, 1(3), 35-51. Recuperado de http://www.anpad.org.br/periodicos/arq_pdf/a_663.pdf

Santos, C. P. dos, \& Fernandes, D. H. Von der (2008). A recuperação de serviços como ferramenta de relacionamento e seu impacto na confiança e lealdade dos clientes. Revista de Administração de Empresas, 48(1), 10-24. doi: 10.1590/S0034-75902008000100002

Sheth, J., Mittal, B., \& Newman, B. (1999). Customer behavior: consumer behavior and beyond. Fort Worth: Harcourt Brace \& Company.

Singh, J. (1991). Understanding the structure of consumer satisfaction evaluation of services delivery. Journal of the Academy of Marketing Science, 19(3), 223-244. doi: 10.1007/BF02726498

Singh, J., \& Sirdeshmukh, D. (2000). Agency and trust mechanisms in consumer satisfaction and loyalty judgments. Journal of the Academy of Marketing Science, 28(1), 150-167. doi: $10.1177 / 0092070300281014$

Sirdeshmukh, D., Singh, S., \& Sabol, B. (2002). Consumer trust, value, and loyalty in relational exchanges. Journal of Marketing, 66(1), 15-37.

Smith, A. K., Bolton, R. N., \& Wagner, J. (1999). A model of customer satisfaction with service encounter involving failure and recovery. Journal Marketing Research, 36(3), 356-372.

Stefan, M., Bowen, D., \& Johnston, R. (2009). Why service recovery fails: tensions among customer, employee, and process perspectives. Journal of Service Management, 20(3), 253-273. doi: $10.1108 / 09564230910964381$

Tax, S. S., Brown, S. W., \& Chandrashekaran, M. (1998). Customer evaluations of service complaint experiences: implications for relationship marketing. Journal of Marketing, 62(2), 60-76. doi: $10.2307 / 1252161$

Thibaut, J., \& Walker, L. (1975). Procedural justice: a psychological analysis. Hillsdale, NJ: Lawrence Erlbaum. 


\section{APÊNDICE}

\section{Variáveis da Pesquisa}

\begin{tabular}{|c|c|}
\hline \multirow{4}{*}{$\begin{array}{l}\text { Justiça } \\
\text { Distributiva }\end{array}$} & Jdist1 - Tenho certeza que o resultado final da minha reclamação foi o esperado. \\
\hline & $\begin{array}{l}\text { Jdist } 2 \text { - O retorno que a XXX me deu em relação à minha reclamação foi exatamente o que } \\
\text { eu esperava. }\end{array}$ \\
\hline & Jdist3 - A minha reclamação foi totalmente atendida. \\
\hline & $\begin{array}{l}\text { Jdist4 - Com base no retorno que tive da minha reclamação, tenho a certeza que a XXX trata } \\
\text { muito bem todas as reclamações que recebe de seus clientes. }\end{array}$ \\
\hline \multirow{5}{*}{$\begin{array}{l}\text { Justiça } \\
\text { Processual }\end{array}$} & Jpro1 - Os funcionários da empresa XXX responderam prontamente a minha reclamação. \\
\hline & Jpro2 - A empresa XXX assumiu imediatamente a responsabilidade pelo meu problema. \\
\hline & $\begin{array}{l}\text { Jpro3 - Certamente quando reclamei, fui tratado (a) muito melhor que em meus outros } \\
\text { contatos com a empresa XXX. }\end{array}$ \\
\hline & Jpro4 - A XXX facilita o contato aos clientes que possuem alguma reclamação. \\
\hline & $\begin{array}{l}\text { Jpro5 - Eu obtive facilidade para expor os detalhes da reclamação aos funcionários da empresa } \\
\text { XXX. }\end{array}$ \\
\hline
\end{tabular}

Justiça Jint1 - Diante do atendimento recebido, tenho a certeza de que os funcionários da empresa Interpessoal $\quad \mathrm{XXX}$ foram honestos comigo.

Jint2 - Os funcionários da empresa XXX ficaram muito interessados em resolver o meu problema.

Jint3 - Os funcionários da empresa XXX se esforçaram para resolver o meu problema.

Jint4 - Os funcionários da empresa XXX deram uma explicação excelente sobre a causa do meu problema.

Jint5 - Eu recebi um pedido de desculpas sinceros dos funcionários da empresa XXX.

Jint6 - Os funcionários da empresa XXX foram muito amáveis comigo.

Satisfação Sat1 - Eu estou plenamente satisfeito com o atendimento da empresa XXX.

Sat2 - Eu realmente gostei de comprar na empresa XXX.

Sat3 - Ser cliente da empresa XXX foi uma experiência muito agradável.

Sat4 - Eu estou certo (a) que fiz a escolha correta quando me tornei cliente da empresa XXX.

Sat5 - Diante da solução recebida, fiquei satisfeito por comprar na empresa XXX.

\begin{tabular}{ll}
\hline Qualidade & Qper1 - O ambiente físico das lojas XXX é muito agradável. \\
Percebida & Qper2 - O ambiente físico das lojas XXX facilita as minhas compras. \\
& Qper3 - Quando um funcionário da XXX se compromete com um prazo, ele é cumprido. \\
& Qper4 - Os funcionários da XXX têm condições de sanar as dúvidas dos clientes. \\
& Qper5 - A XXX facilita a solução dos problemas no caso de uma reclamação. \\
& Qper6 - Tenho a certeza de que a empresa XXX oferece serviços de qualidade. \\
\hline Confiança & Conf1 - A empresa XXX coloca os interesses dos seus clientes em primeiro lugar. \\
& Conf2 - A empresa XXX honra as suas promessas e os seus compromissos como seus clientes. \\
& Conf3 - Diante da solução recebida, tenho a certeza que posso confiar no que os funcionários \\
& da empresa XXX dizem. \\
& Conf4 - Diante do resultado recebido, tenho a certeza de que posso confiar na empresa XXX.
\end{tabular}

Valor Percebido Val1 - Os preços praticados pela empresa XXX são muito vantajosos.

Val2 - Em relação ao tempo gasto para realizar as minhas compras, tenho a certeza de que a empresa XXX me ofereceu vantagens que não encontro no mercado.

Val3 - O esforço total necessário para realizar uma compra na empresa XXX é muito satisfatório quando considero os custos que tive e os benefícios que recebi.

Val4 - A facilidade que possuo em negociar com a empresa XXX é muito importante para 


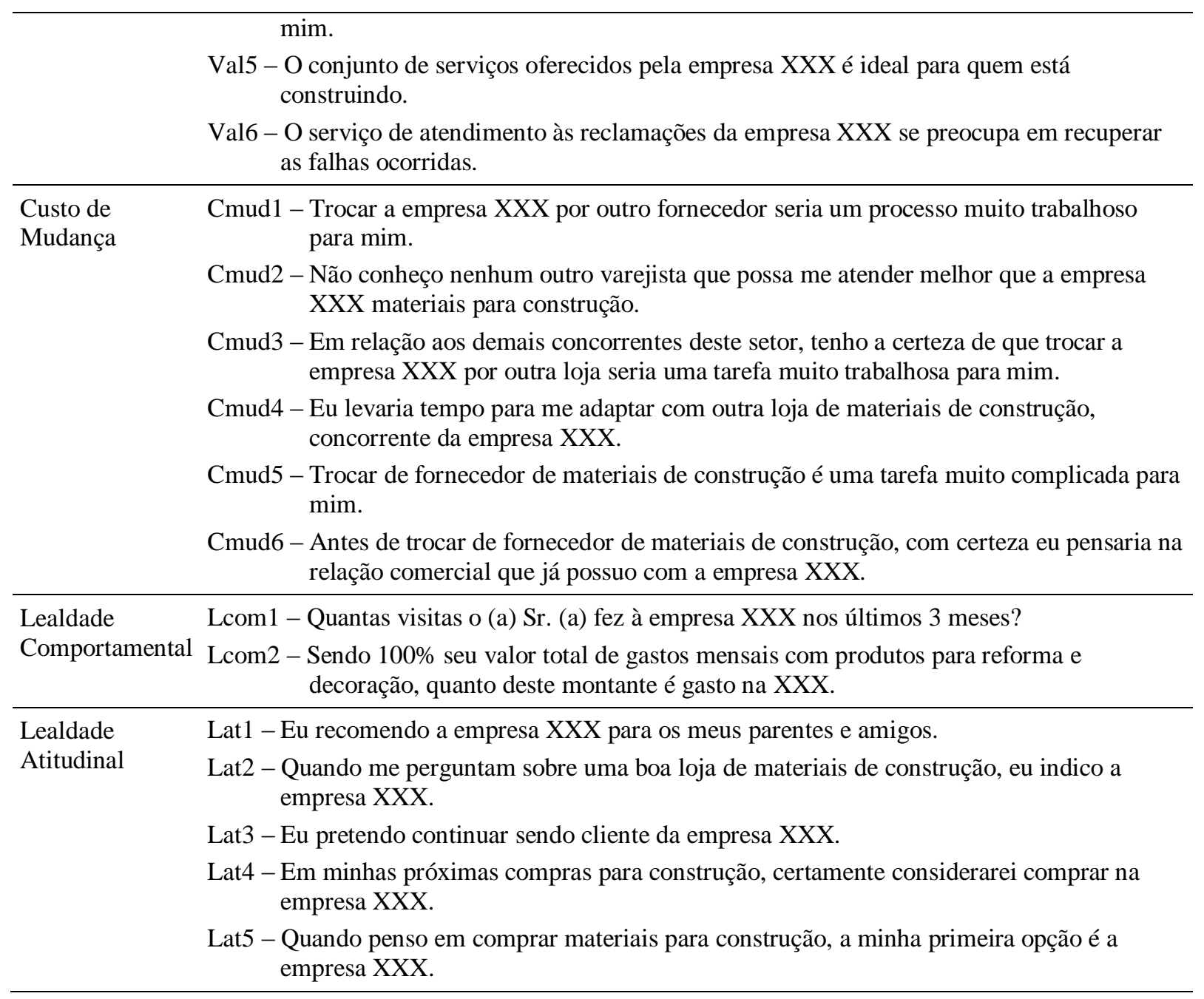

